\title{
LETTER
}

\section{Professor Remolo Ciola, a Master and a Genius}

\author{
Celso Blatt \\ GC and GC/MS Application Scientist \\ Agilent Technologies Brasil \\ Barueri, SP, Brazil
}

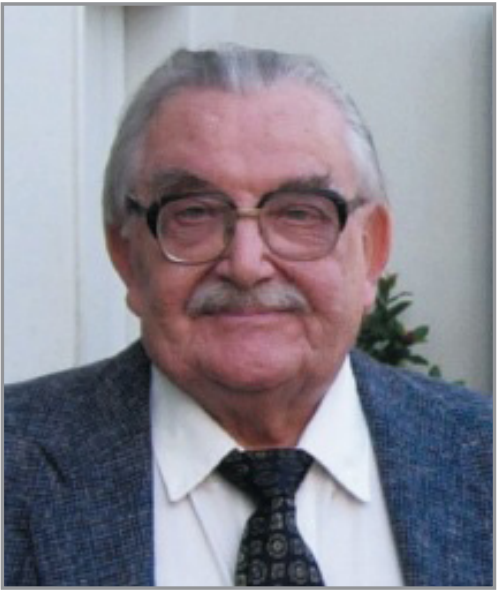

Remolo Ciola

In 1984, when I was in my last year as an undergraduate in Industrial Chemistry at the Federal University of Santa Maria (UFSM), Santa Maria, RS, Brazil, I heard about Professor Remolo Ciola. A Professor from UFSM introduced me to the book "Fundamentos da Catálise" written by Prof. Ciola (Figure 1). I liked the subject catalysis and contacted Prof. Ciola to see whether I could discuss the possibility of doing a Master's degree at the University of São Paulo (USP) in São Paulo, SP, where he was a Professor.

Arriving in São Paulo for this initial conversation, I found out that Prof. Ciola had a company called "Instrumentos Científicos CG Ltda", on Avenida Domingos de Moraes, in the south area of the city of São Paulo, where the meeting would take place. When I arrived at the company, Prof. Ciola welcomed me, but said that despite having guided several people in catalysis, he was no longer working with this technique at USP. He made me a proposal that surprised me: "How about working with gas chromatography and analyzing sugar?". Until that moment I had never heard of gas chromatography and no chromatography was used at UFSM at that time. Prof. Ciola clarified that to analyze sugars I would use chemical reactions to attack the $\mathrm{OH}$ groups of the sugars and exchange them for an acetyl or trimethyl silicon and make these sugars volatile. To convince me, he said that he would have to test catalysts for these derivatization reactions.

At UFSM, the first Master's class would open in 1985, so I took a qualification test for the Master's degree in Santa Maria and at USP. As the São Paulo Research Foundation (FAPESP) scholarship came out first, I decided to come to São Paulo.

Prof. Dr. Remolo Ciola was already well known and respected in 1985 when I arrived at USP. He was born in Italy in 1923 and came to Brazil at a young age. He graduated in chemistry at USP in 1948 and taught at the Technological Institute in Aeronautics (ITA) in São José dos Campos, SP, and at the Engineering School of Mauá in São Caetano do Sul, SP, before teaching at USP. Prof. Ciola defended his Master's degree in the United States in 1958 and his Doctorate at USP in 1961. For many years he was director of the research center at the "Refinaria União" (Petrobrás oil refinery) in Mauá, SP. Despite having already started experiments with chromatography in 1954, Prof. Ciola built the first gas chromatograph with Thermal Conductivity Detector (TCD) in 1958 to meet the

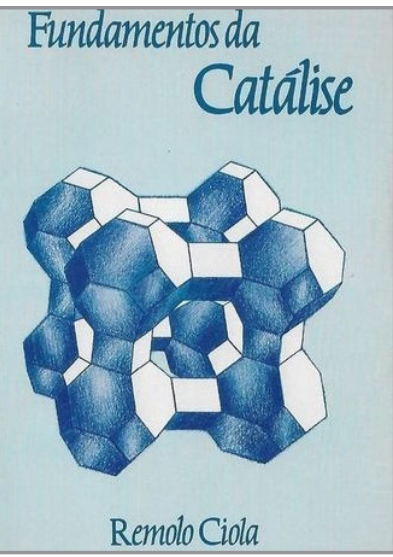

Figure 1. Cover of the book entitled "Fundamentos da Catálise" by Remolo Ciola. needs of the refinery. He was a pioneer in Latin America, building this first gas chromatograph with parts

Cite: Blatt, C. Professor Remolo Ciola, a Master and a Genius. Braz. J. Anal. Chem., 2021, 8 (31), pp 16-21. doi: http://dx.doi. org/10.30744/brjac.2179-3425.letter-cblatt 
and supplies developed in his laboratory. At that time, the refinery acquired a lot of knowledge of catalysis and polymers.

The company "Instrumentos Científicos CG Ltda" was created in 1961 in the garage of Prof. Ciola's house, together with his nephew Ivo Gregori. In the early years of the company, Prof. Ciola was the chemist and inventor and his nephew played the role of electronics and mechanic. It took me years to discover that the name CG was not Gas Chromatography, but the initials of the surnames Ciola and Gregori. The company's objective was to produce gas chromatographs to supply industries, universities and laboratories that performed chemical analysis. The CG Company grew a lot due to the market reserve in Brazil that could not import equipment if there was a similar national product, and also with the Brazilian Pro-alcohol program where many plants bought gas chromatographs for alcohol analysis.

Dr. Ciola, as many called him, is the author of more than 170 scientific and technological papers, of several patents on catalytic projects and analytical instruments and the author of books on catalysis and gas and liquid chromatography. The chromatography books of his own are shown in Figure 2.
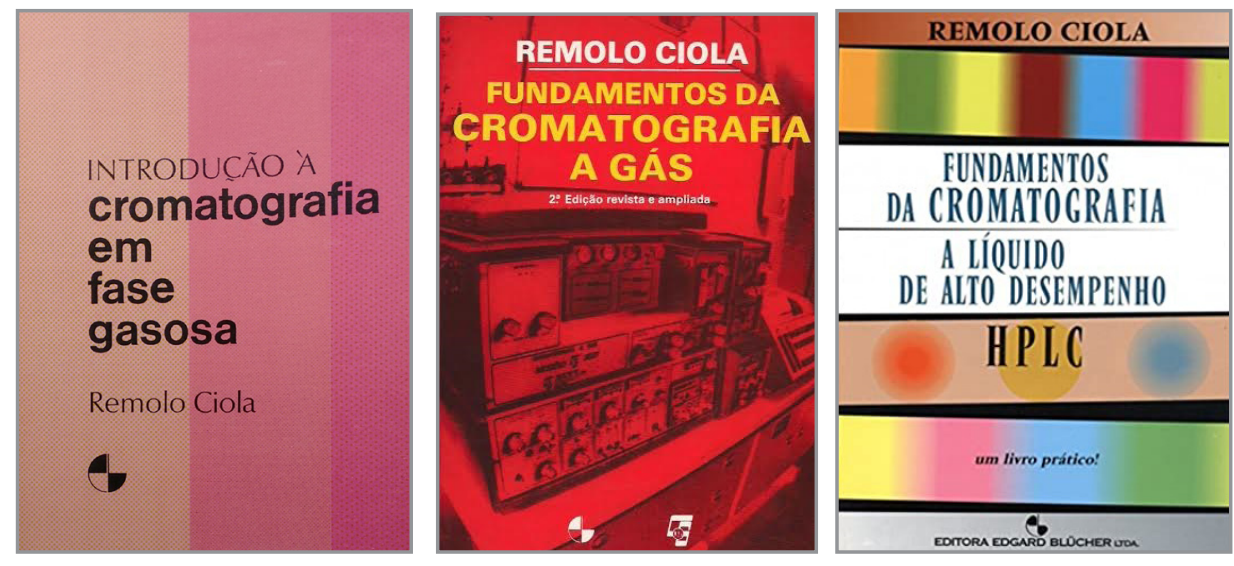

Figure 2. Covers of the three books on chromatography by Remolo Ciola. From left to right: "Introdução à cromatografia em fase gasosa", "Fundamentos da Cromatografia a Gás", "Fundamentos da Cromatografia a Líquido de Alto Desempenho".

I started postgraduate classes in 1985 at USP, with the practical part being performed in the CG Company itself, which was moving to a new address on Avenida Vereador Jose Diniz in the neighborhood of Brooklin, São Paulo. Postgraduate classes with Prof. Ciola were very good and always well attended. A certain course that I took, Prof. Ciola applied a chemistry test on the first day of class on basic knowledge such as chemical structure, $\mathrm{pH}$ and chemical functions; half of the class did not get a score of 5 in the test and were prevented from taking the course. He did not admit those to a postgraduate course who did not have a basic knowledge of chemistry. The postgraduate courses given by Prof. Ciola at USP were Catalysis, Polymers, Gas chromatography and Liquid chromatography. Prof. Ciola has always impressed me with his knowledge of basic chemistry, organic chemistry, synthesis, polymers and catalysts. In addition, he was very good at designing and creating technological solutions to solve problems or create new things. He did the sketches, and then passed them on to a professional designer at CG Company where the workshop produced the piece.

During my Master's I used the gas chromatograph in Figure 3 to perform the analysis of derivatized sugars. It was a gas chromatograph with a split injector and flame ionization detector (FID) and an oven temperature that was constant and set on the button in the red square in Figure 3. This chromatograph did not have a display to indicate the real temperature in the oven, but had red LEDs above the mentioned button. If the LED on was the LED to the left of the central LED, it indicated that the temperature had not yet reached the set temperature. The illumination of the central LED theoretically indicated that the oven had reached the expected temperature. I needed to make a temperature ramp for my analysis, which required 
Blatt, C.

me to use a stopwatch. I injected the sample and every minute I turned the knob up by 10 degrees. I worked like this for a year until Prof. Ciola provided a marvel of the time, which was the box on the side of the Figure 3, a linear temperature programmer. With this box we no longer needed to use the timer for temperature ramps, and it has since become automatic. I even saw other users in the CG Company using the recorder, but Prof. Ciola was generous and gave me an integrator/recorder with which to handle the data.

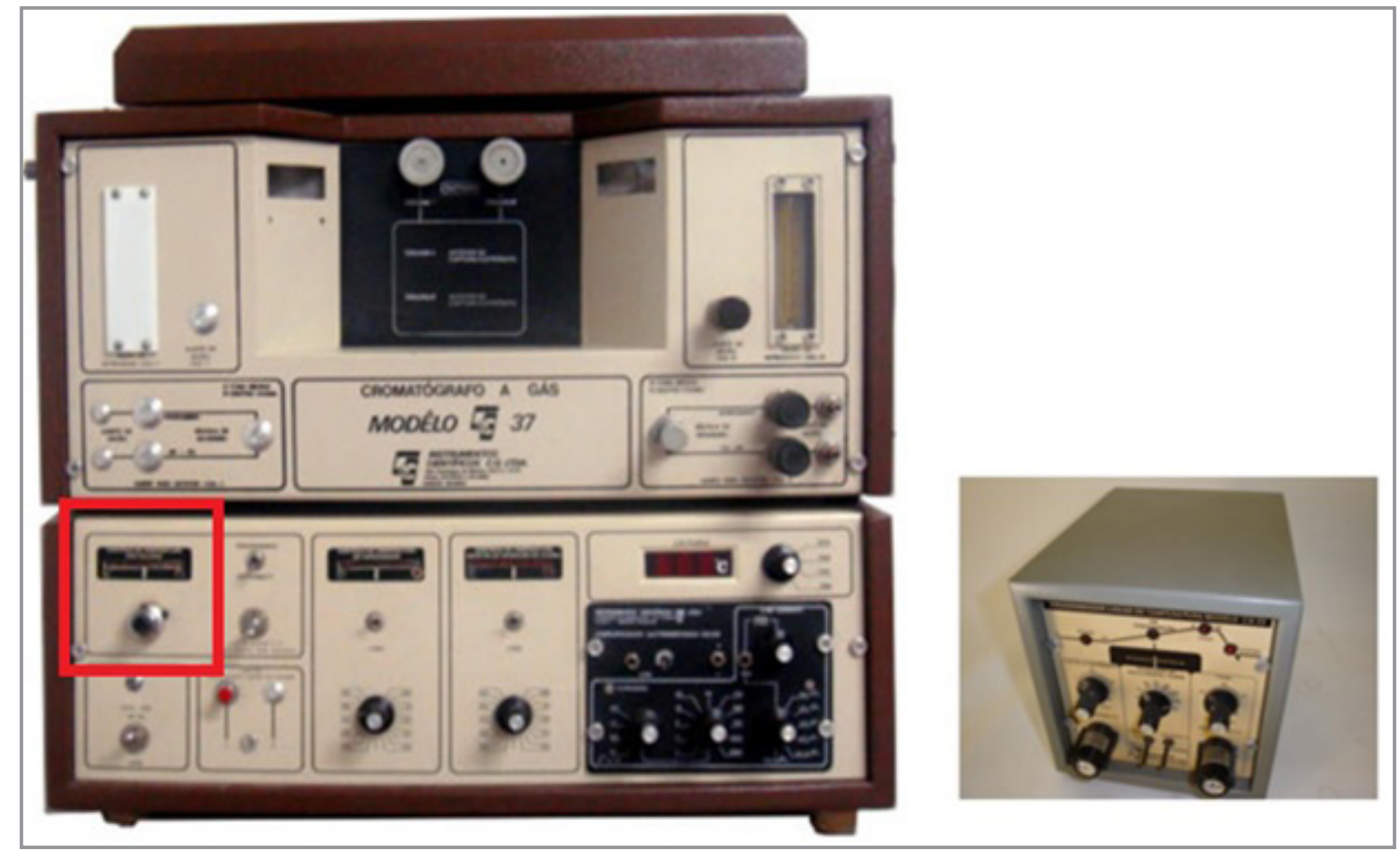

Figure 3. Original gas chromatograph Model 37 from CG Instrumentos Científicos Ltda.

It caught my attention that the employees at CG Co. did everything from manufacturing all the pieces to preparing the packed and capillary columns. I even helped to pack very long columns where a person was on an upper floor transferring the stationary phase with a funnel into the column and I was on the lower floor hitting the column with a piece of wood, for a good packaging of the column. I also followed how the capillary columns were prepared. CG Co. bought the fused silica tube and made the preparation and deposition of the stationary phase film. Working at CG Co. was very pleasant, and it felt like a family. The photo below (Figure 4) taken at Prof. Ciola's house shows his wife Celia and son Remolo on the left, and me and other graduate students Silvana, Celina and Rivana on the left.

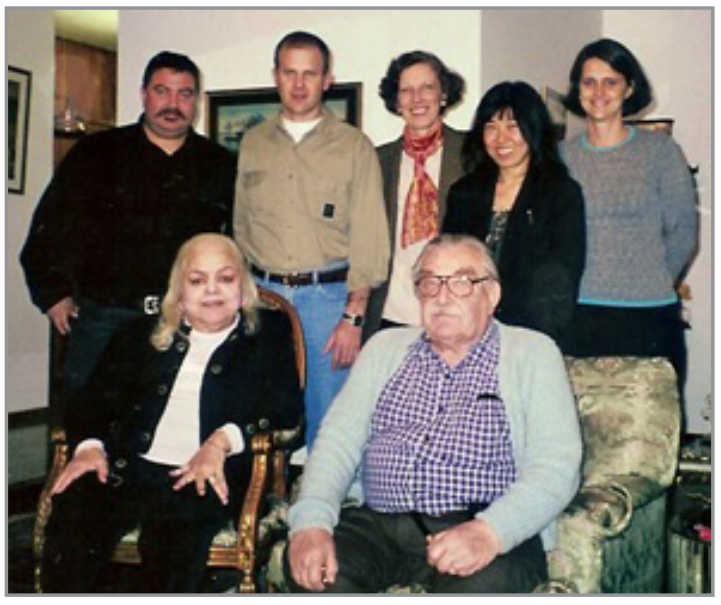

Figure 4. Photo taken at Prof. Ciola's house. From left to right: Célia and Remolo Ciola, seated; Remolo Ciola Filho, Celso Blatt, Silvana Pisani, Celina Takayama, Rivana Marino, standing. 
Dona Celinha, as Prof. Ciola called his wife, was an engineer trained in Rio de Janeiro, Brazil. She told me how difficult it was to be a female engineer when studying at the Institute of Nuclear Engineering in Rio de Janeiro. Son Reminho also worked at CG Co. and taught me how to make spreadsheets in Lotus 123, the precursor to Excel.

Prof. Ciola was always very innovative, read a lot and subscribed to several scientific journals. At that time there was no Google, and Prof. Ciola asked me to do a bibliographic review of the last decade. I spent about 3 months in the USP library consulting the famous Chemical Abstracts; when I found a reference, I had to look for the journal with the article, take a Xerox copy and take it to read at home. In the Master's, I tested several reactions to derivatize the sugars and found that with hexamethyldisilazane (HMDS) and imidazole as a catalyst, the reaction with $\mathrm{OH}$ groups happened quickly and efficiently. To write the thesis, I used a computer, but in 1987 there was no Word, no spell checker, and no Paint, or any of the other wonders we have today. The computer used was an Apple, the text editor Wordstar had no accent; the printing was done on a dot matrix printer. The figures had to be glued to the text and we used a concealer to avoid showing glue in the figures. In defense of my Master's thesis, Prof. Ciola pointed out that it was one of the first USP theses typed on a computer, but a Professor at the examining board complained that it had no accents in the text. Thanks to the arguments of Prof. Ciola my Master's was approved.

In 1986, when Professor Ciola and I went to the $1^{\text {th }}$ Latin American Chromatography Congress (Colacro) in Rio de Janeiro, we realized that chromatography using supercritical fluids was one of the most talked about subjects at the congress. In 1987, when I defended my Master's degree, Prof. Ciola made me the offer to work at CG Co. as an employee and also invited me to do a doctorate in Supercritical Fluid Chromatography (SFC) and Supercritical Fluid Extraction (SFE). For someone who came to São Paulo with plans to do a Master's degree and return to the South of Brazil in two years, it was a turnaround that today means I have spent more than 35 years in São Paulo. Prof. Ciola's doctoral proposal was to study chromatography with supercritical fluids and also perform extraction using supercritical fluids. At the time, there was no commercial equipment, so we had to develop the hardware, which was what encouraged Prof. Ciola. To use carbon dioxide as a fluid, we needed liquid $\mathrm{CO}_{2}$; at the time, it was uncommon. It was easy to solve this, however, as we took a cylinder of $\mathrm{CO}_{2}$ fire extinguisher and put it upside down and took the liquid. To pump the $\mathrm{CO}_{2}$, we used a Haskel multiplier pump that Prof. Ciola had bought to pack the HPLC columns. For restricting flow after the column, Prof. Ciola bought tubes of fused silica with 5 and 10 microns. In addition to chromatography, the extraction process using supercritical $\mathrm{CO}_{2}$ was studied; the genius Prof. Ciola took action again by designing a heated restrictor after extraction and inside the injector of a GC/MS. We then had an online system SFE-GC/MS. This online coupling using the heated restrictor shown in Figure 5 yielded my first article in an international journal in 1991 and participation in the International Symposium on Capillary Chromatography in Riva Del Garda, Italy. The drawing shows how Prof. Ciola had a brilliant mind and was a good draftsman. The drawing below was done by a professional draftsman, but the sketch and idea were by Prof. Ciola.

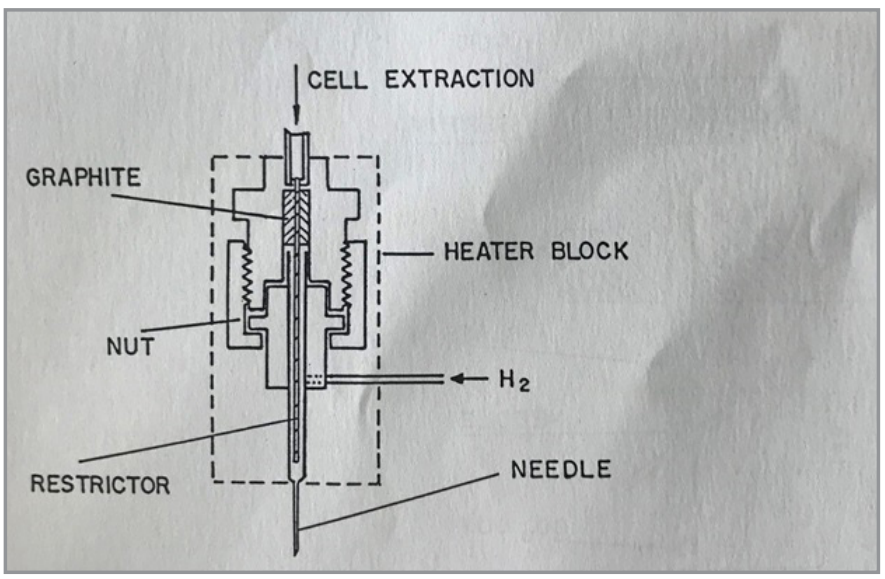

Figure 5. Schematic diagram of the interface between extraction cell and PTV insert in online SFE-PTV-GC. 
During my doctorate, talking to Rita who made the capillary columns at the CG Co., I discovered once again how Prof. Ciola was a genius. After cutting the 30 meters of a capillary column and wrapping it in the basket, the first part of the preparation process was to clean the tube and leave the surface wettable and then lock the phase in the silica. As they had difficulties with this first stage, Prof. Ciola changed the process to treat the $\mathrm{OH}$ groups of silica with HMDS and imidazole, which worked. Prof. Ciola's genius was that he used my Master's degree to solve a problem in the production of capillary columns.

The CG Co., in addition to manufacturing its own gas chromatographs, also represented Shimadzu for a while and that's when I learned to use GC/MS. I even installed some GC/MS and gave training. Times started to get difficult in CG Co. because they lost Shimadzu's representation and the market reserve in Brazil ended. In this way, eight CG employees, including myself, made a deal and left CG Co. to set up a new company in February 1992, named Analítica, known today as Nova Analítica. Prof. Ciola remained at CG Co. until 1998, and the company's name was changed to "CG Científica". I stayed at Analítica for six months, when, in September 1992, the company Hewlett Packard invited me to work in support of the SFE and SFC instruments that they were producing and selling. In 1999, Hewlett Packard separated the areas of computing and measurement. The measurement area became Agilent Technologies, where I work today.

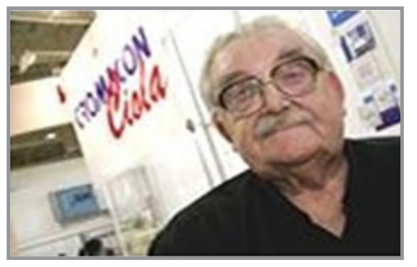

In 1999, Professor Ciola started his own company called Cromacon and continued to produce national gas chromatographs and make packed and capillary columns. Figure 6 is a photo of Prof. Ciola at the Cromacon Ciola booth at an instrument exhibition.

Figure 6. Remolo Ciola at the

Cromacon Ciola booth at an instrument exhibition.

The photo below (Figure 7) was taken on the occasion of Prof. Ciola's birthday in 2009. He used to say in classes that they washed their hands with benzene at the "Refinaria União". At the time nobody knew that benzene is a carcinogen substance. Prof. Ciola passed away in 2010, but he lived his 87 years very well.

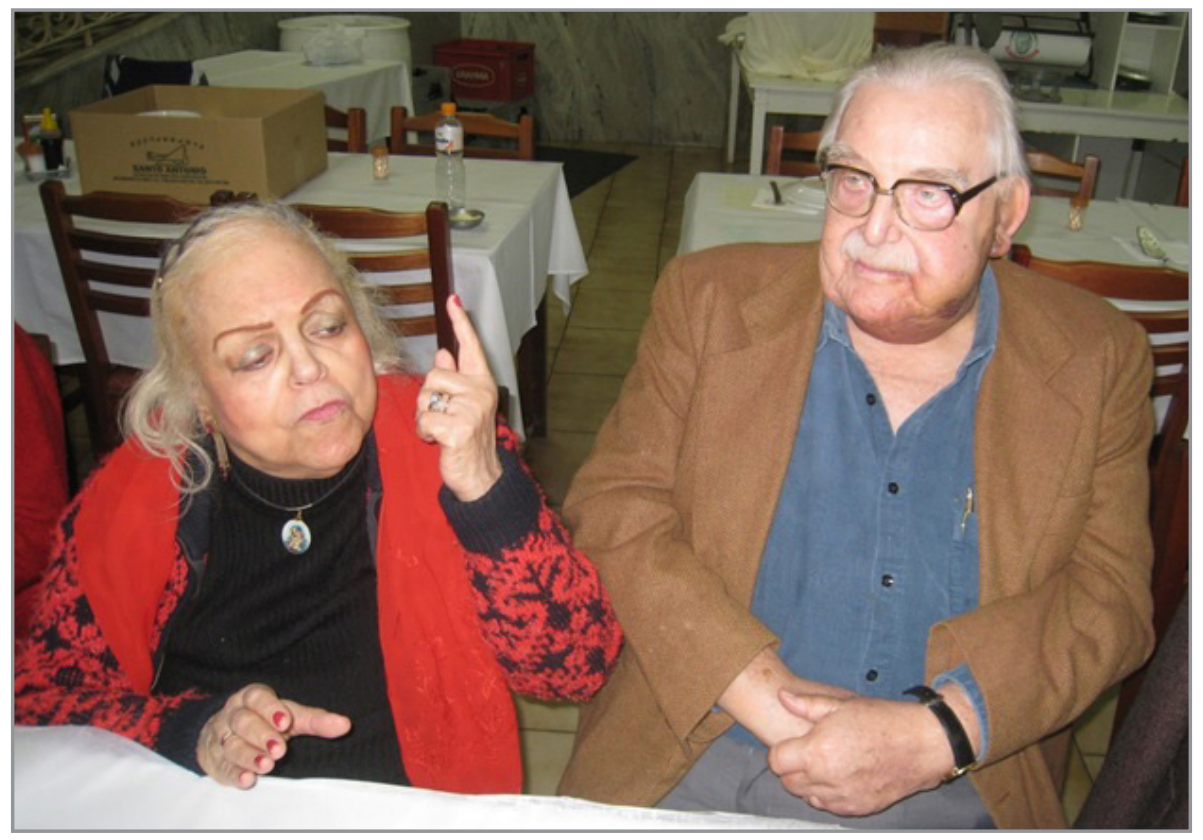

Figure 7. Remolo Ciola and his wife Celia Ciola. 
Thank you Prof. Dr. Ciola for your teachings, for all your dedication as well as for your contribution to the Brazilian chromatography.

For more information about Prof. Ciola and his biography, I recommend the In Memoriam entitled "Remolo Ciola, uma mente inventiva, um verdadeiro pioneiro" by Luiz Bravo and Silvana Pisani, published in the journal Scientia Chromatographica, 2010, Volume 2, № 3, pages 94-96, available through the link: http://iicweb.org/scientiachromatographica/

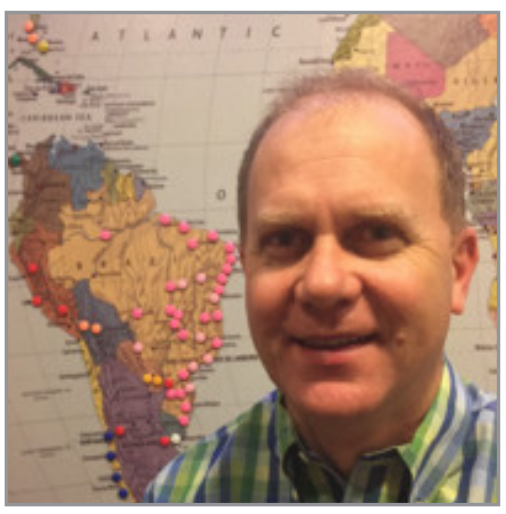

Celso R. Blatt is graduated in Industrial Chemistry (1984) from the Federal University of Santa Maria, Santa Maria, RS, Brazil, and took his Master's (1987) and Doctorate (1992) in Analytical Chemistry at the University of São Paulo, SP, Brazil. From 1987 to 1992, he was a Researcher in Analytical Instrumentation at Instrumentos Científicos CG Ltda, SP. In 1992, he started working as a Support Engineer at Hewlett Packard Co. then Agilent Technologies Brasil where he still works as an Applications Scientist. in CV 